\title{
Identification of significant molecules and signaling pathways between 2D and 3D culture methods of renal cancer cells
}

Mengyao Wang, Hongmei Guo, Hanming Gu*, Mason Zhang ${ }^{1}$

${ }^{1}$ SHU-UTS SILC School, Shanghai University, Shanghai, China

*Corresponding author: Hanming Gu, SHU-UTS SILC School, Shanghai University, Shanghai, China

laygmp@gmail.com 


\section{Abstract}

The majority of cancer studies are conducted with the two-dimensional (2D) culture method, which does not reflect tumor in vivo structure. The 3D culture method can form free bundles of cancer cells and spheroid, which mimics the tumor microenvironment in vivo. However, the molecules and signaling pathways between the $2 \mathrm{D}$ and $3 \mathrm{D}$ culture methods are still unknown. In this study, we aim to identify the key molecules and signaling pathways by analyzing the RNA-seq data. The GSE190296 was created by the BGISEQ-500 (Homo sapiens). The KEGG and GO analyses indicated sulfur compound metabolic process and regulation of leukocyte mediated immunity are the major differences between 2D and 3D renal cancer cell cultures. Moreover, we figured out several interactive genes including MYC, EGF, VEGFA, STAT3, NOTCH1, CAT, CCND1, HSPA8, DLG4, and HSPA5. Our study may provide new knowledge on the differences between 2D and 3D cancer cell cultures.

\section{Introduction}

In the US and Europe, renal cancer was ranked as the high common malignancy in men each year'. Though surgery is an effective therapy for early diagnosed patients, a number of patients suffer recurrence or metastatic cancers thereafter ${ }^{2}$. Limited treatment methods have been doable for these patients. The classic signs of pain, hematuria and flank mass are indicative of advanced diseases. There are about $30 \%$ of patients with renal cancer showed metastatic diseases, and $45 \%$ with localized diseases ${ }^{3}$.

Radical nephrectomy is the standard method for renal cancer and no chemotherapeutic regimen is considered as a standard method ${ }^{4}$. Improvements in molecular knowledge of resistance have contributed to the identification of new drug targets ${ }^{5}$. Many candidate agents are under evaluation, which may play a vital role in combination therapy ${ }^{6}$. One of the important factors in vitro studies is the culture method ${ }^{7}$. Traditionally, the anti-cancer drugs have been tested in 2D cultured cancer cells, but this culture method is not suitable for determining the tumor microenvironment created by the 3D culture method ${ }^{8}$. Thus, the $3 \mathrm{D}$ culture method is better than the $2 \mathrm{D}$ culture method to mimic the true environment of renal cancer. 
In this study, we compared and analyzed the methods of cancer cells culture by using the RNA-seq data. We discovered a number of DEGs and significant signaling pathways. We then performed the gene enrichment and protein-protein interaction (PPI) network analysis to obtain the interacting map and key genes. These genes and biological processes may provide new knowledge of renal cancer cells in different environments.

\section{Methods}

\section{Data resources}

Gene dataset GSE190296 was downloaded from the GEO database. The data was produced by the Illumina NextSeq 500 (Homo sapiens) (Military Institute of Medicine, Szaserow 128, Warsaw, Poland). The analyzed dataset includes three RenCa cells cultured by the 2D method and three RenCa cells cultured by the 3D method.

\section{Data acquisition and processing}

The data were organized and conducted by the $\mathrm{R}$ package as previously described ${ }^{9-13}$. We used a classical t-test to identify DEGs with $\mathrm{P}<0.05$ and fold change $\geq 1.5$ as being statistically significant.

The Kyoto Encyclopedia of Genes and Genomes (KEGG) and Gene Ontology (GO) KEGG and $\mathrm{GO}$ analyses were performed by the $\mathrm{R}$ package (ClusterProfiler) and Reactome ${ }^{12,14,15}$. $\mathrm{P}<0.05$ was considered statistically significant.

Protein-protein interaction (PPI) networks

The Molecular Complex Detection (MCODE) was used to create the PPI networks. The significant modules were produced from constructed PPI networks and String networks (https://string-db.org/). The biological processes analyses were performed by using Reactome (https://reactome.org/), and $\mathrm{P}<0.05$ was considered significant.

\section{Results}

\section{Identification of DEGs in renal cancer cells between 2D and 3D culture systems}


To determine the effects of different cancer cell culture systems, we analyzed the RNAseq data of renal cancer cells from 2D and 3D culture systems. A total of 1281 genes were identified with the threshold of $P<0.01$. The top up- and down-regulated genes were shown by the heatmap and volcano plot (Figure 1). The top ten DEGs were listed in Table 1.

\section{Enrichment analysis of DEGs in renal cancer cells between 2D and 3D culture systems}

To further understand the impacts on different culture systems in renal cancer cells, we performed the KEGG and GO enrichment (Figure 2). We figured out the top ten KEGG items including "Human cytomegalovirus infection", "Epstein-Barr virus infection", "Cellular senescence", "Phagosome", "Lysosome", "Antigen processing and presentation", "Glutathione metabolism”, "Platinum drug resistance”, "Viral myocarditis", and "Drug metabolism - cytochrome P450". We identified the top ten BP of GO items, which contains "sulfur compound metabolic process", "Regulation of leukocyte mediated immunity", "Cellular modified amino acid metabolic process", "Regulation of adaptive", "Immune response based on somatic recombination of immune receptors built from immunoglobulin superfamily domains", "Glutathione metabolic process", "T cell mediated cytotoxicity", "Regulation of T cell mediated cytotoxicity", "Antigen processing and presentation of endogenous peptide antigen", "Antigen processing and presentation of endogenous peptide antigen via MHC class I", and "Antigen processing and presentation of endogenous antigen". We identified the top ten CC of GO items, which contains "Apical part of cell", "Vacuolar membrane", "Collagen-containing extracellular matrix", "Apical plasma membrane", "Early endosome", "Endosome membrane", "Lysosomal membrane", "Lytic vacuole membrane", "MHC class I protein complex", and "Phagocytic vesicle membrane". We also identified the top ten MF of GO items including "Amide binding", "Peptide binding", "Sulfur compound binding", "Transferase activity, transferring alkyl or aryl (other than methyl) groups", "Glutathione transferase activity", "TAP binding", "TAP1 binding", "Glutathione binding", "Oligopeptide binding”, and "TAP2 binding". 


\section{PPI network and Reactome analyses}

To explore the potential relationship among the DEGs, we created the PPI network by using 1059 nodes and 3783 edges. The combined score $>0.2$ was set as a cutoff by using the Cytoscope software. Table 2 indicated the top ten genes with the highest scores. The top two significant modules were presented in Figure 3. We further analyzed the PPI and DEGs with Reactome map (Figure 4) and identified the top ten biological processes including "Glutathione conjugation", "Response of EIF2AK1 (HRI) to heme deficiency", "RUNX3 regulates WNT signaling", "NGF-stimulated transcription", "NrCAM interactions", "Removal of aminoterminal propeptides from gammacarboxylated proteins", "CHL1 interactions", "RUNX3 regulates NOTCH signaling", "Gamma-carboxylation, transport, and amino-terminal cleavage of proteins", and "ATF6 (ATF6-alpha) activates chaperones" (Supplemental Table S1).

\section{Discussion}

Cell culture is important for cancer research. Recently, most cells are cultured by the 2D method, but several studies showed 3D cell culture had shown improvements such as cell morphology and number monitoring, proliferation, differentiation, and drug metabolism ${ }^{16}$. However, the molecular difference of $2 \mathrm{D}$ and $3 \mathrm{D}$ culture is still not clear.

By analyzing the KEGG and GO enrichment, we found that "sulfur compound metabolic process" and "regulation of leukocyte mediated immunity" are the major differences between 2D and 3D renal cancer cell culture. Sulfur metabolism is controlled by LIAS that is required for the functions of the tricarboxylic acid (TCA) cycle, which stimulates mitochondrial oxidative metabolism and cancer progression. The disorder of metabolism is a potential hallmark of cancer. Nathan $P$ Ward et al found that sulfur metabolism is controlled by LIAS that is required for the functions of the tricarboxylic acid (TCA) cycle, which stimulates mitochondrial oxidative metabolism and cancer progression ${ }^{17,} 18$. Moreover, Mariarita Brancaccio et al found that sulfur compounds can inhibit the activity of $\mathrm{y}$-glutamyl transpeptidase in cancer cells ${ }^{19}$. Renal cancer is considered an immunogenic tumor, which involves the mediate immune dysfunction by eliciting the immune cells including $T$ cells and macrophages into the tumor microenvironment ${ }^{20}$. 
Andrea Muto et al reported the novel renal cancer therapy by targeting the immune checkpoint inhibitors ${ }^{21}$.

In this study, we also identified several interactive molecules by comparing the 2D and 3D methods in culturing renal cancer cells. Emelyn $\mathrm{H}$ Shroff et al found the overexpression of MYC promotes renal cancers through glutamine metabolism ${ }^{22}$. Claire Bouvard et al also found inhibition of MYC by small molecules can inhibit cancer growth in rodent xenograft models ${ }^{23}$. The circadian clocks and their downstream factors are responsible for a variety of physiological and pathological functions including metabolism, aging, and immunity ${ }^{24-34}$. Interestingly, Jamison B Burchett et al found that MYC in cancer cells can disturb the molecular clock, whereas the clock disruption in cancer can promote MYC ${ }^{35}$. Justin P Favaro et al found that the epidermal growth factor (EGF) is critical for tumor progression in renal cancers, which can be considered as a potential drug target ${ }^{36}$. VEGFA is an important mediator of angiogenesis and plays a vital role in cancer angiogenesis and progression ${ }^{37}$. STAT3 has a crucial role in the progression of different cancers and its activation is identified as an important target for cancer therapy ${ }^{38}$. GPCR/RGS signaling regulates the majority of biological processes including immunity, metabolism, aging, and cancer $^{39-50}$. Interestingly, Stéphane Pelletier showed that GPCR agonists stimulate tyrosine phosphorylation of STAT3 proteins in a Rac-dependent manner ${ }^{51}$. Shangwen Liu et al found the functions of Notch1 are responsible for mediating PTEN/PI2K/AKT pathway in renal cancers ${ }^{52}$. Necip Pirinççi et al found the serum CAT activity was significantly decreased in patients with renal cancers by comparing the controls ${ }^{53}$. As a tumor biomarker, the upregulation of cyclin D1 has the role of predicting the favorable prognosis in patients with renal cancers ${ }^{54}$. Jun $\mathrm{Li}$ et al found HSPA8 is a potential prognostic factor to predict the survival of patients with $\mathrm{AML}^{55}$. Yun Ye et al found DLG4 is a potential prostate cancer marker by analyzing the mRNA-miRNA-IncRNA database ${ }^{56}$. Shangqing Song et al found the urinary exosome miR-30c-5p can inhibit the progression of renal cancers by targeting HSPA5 $^{57}$.

In conclusion, this study found the significant genes and biological processes between the 2D and 3D culture methods in renal cancer cells. The "sulfur compound metabolic process" and "regulation of leukocyte mediated immunity" are the top affected 
signalings between the different culture methods. Our study may provide novel insights for the treatment of renal cancers in vitro.

\section{Author Contributions}

Mengyao Wang, Hongmei Guo: Methodology and Writing. Hanming Gu, Mason Zhang: Conceptualization, Writing- Reviewing and Editing.

\section{Funding}

This work was not supported by any funding.

\section{Declarations of interest}

There is no conflict of interest to declare. 

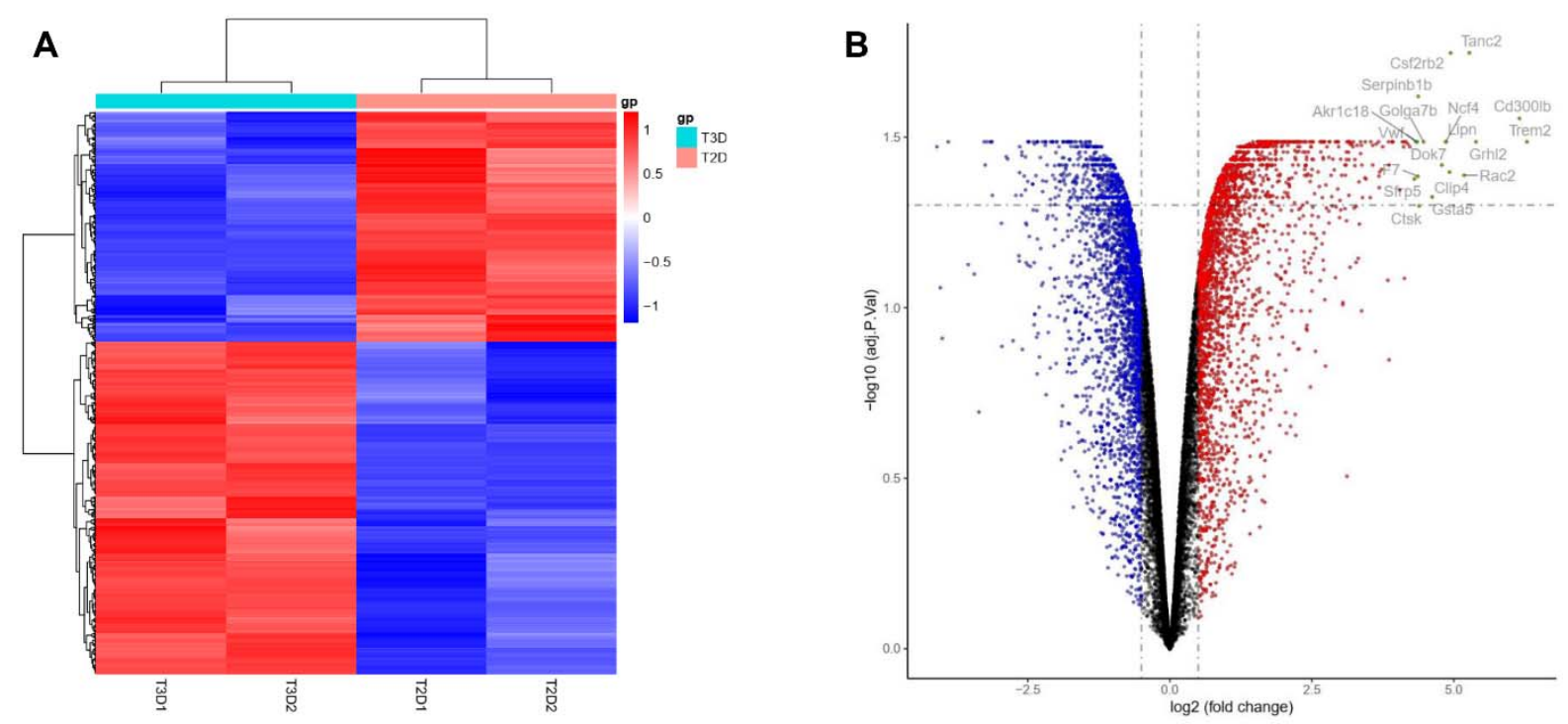

Figure 1. Heatmap and volcano plot in renal cancer cells between 2D and 3D culture systems

(A) Heatmap of significant DEGs. Significant DEGs $(P<0.05)$ were used to construct the heatmap. T2D, tumor cells of 2D culture; T3D, tumor cells of 3D culture.

(B) Volcano plot for DEGs in renal cancer cells between 2D and 3D culture systems. The most significantly changed genes are highlighted by grey dots. 
A

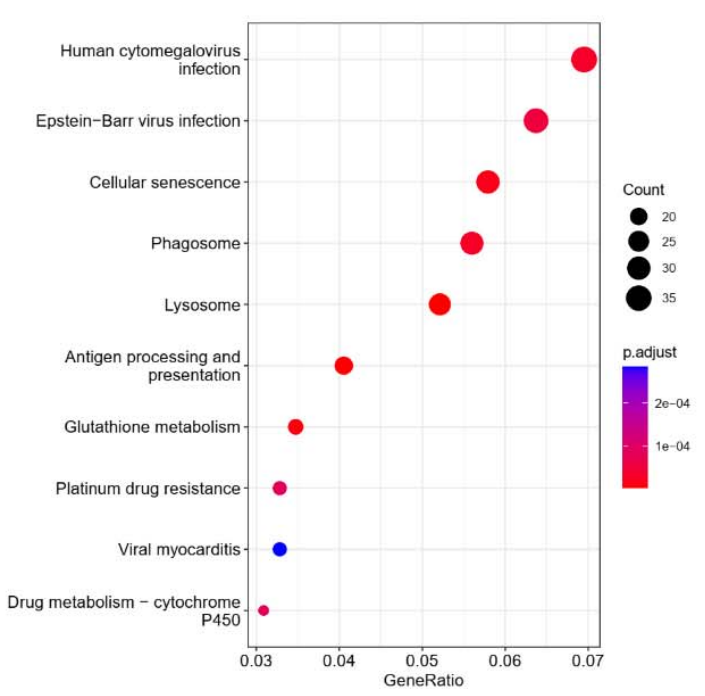

C

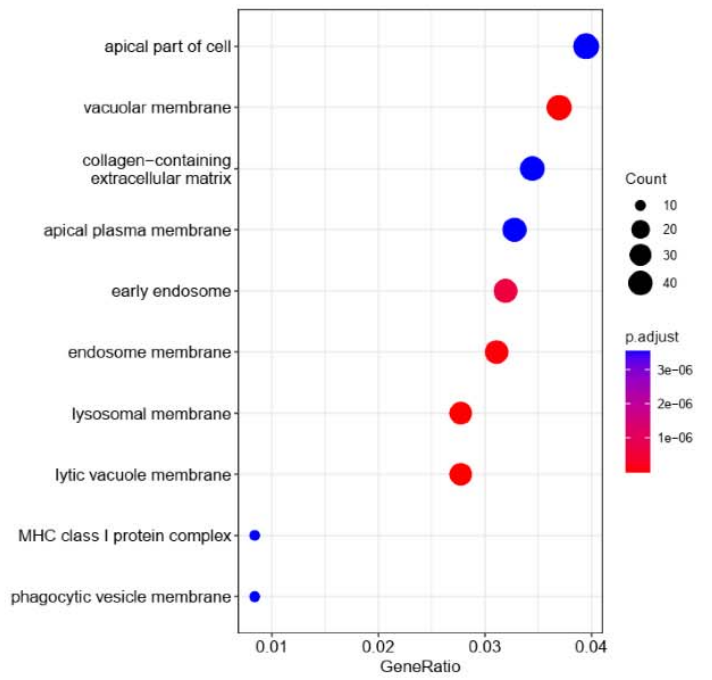

B

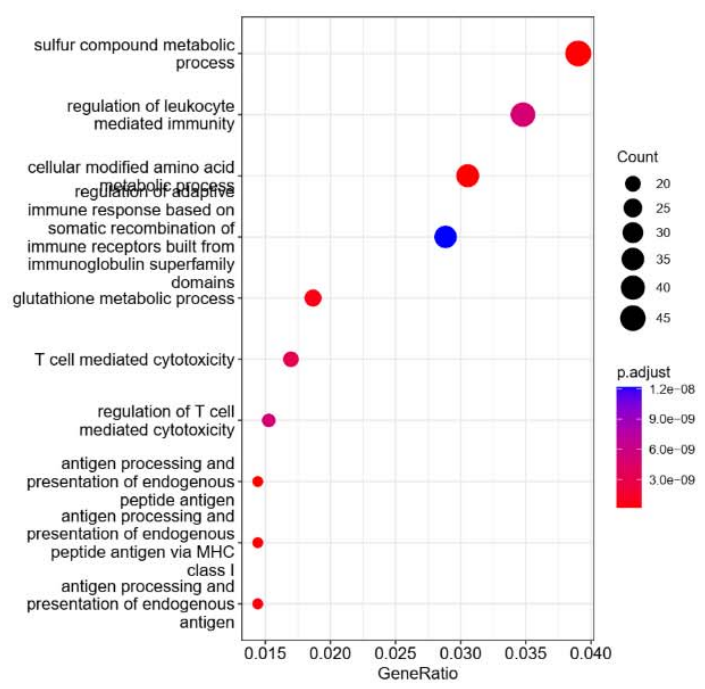

D

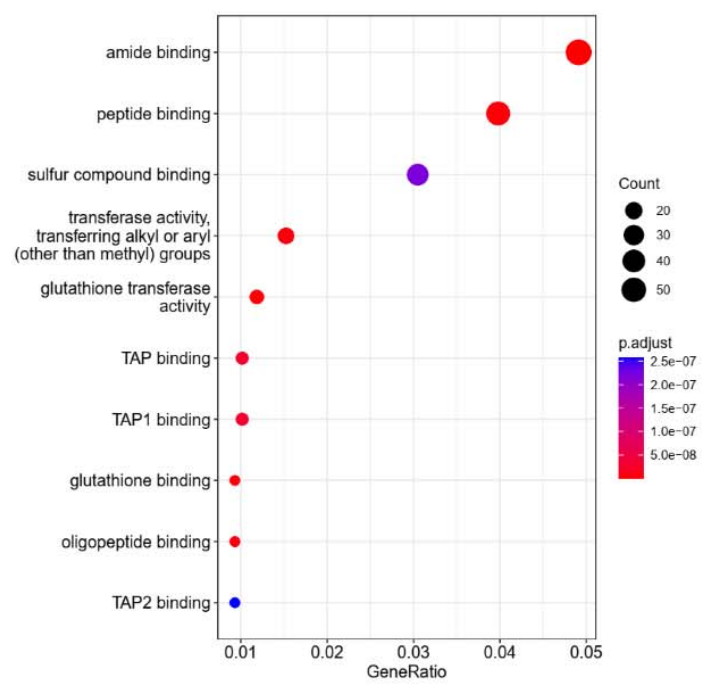

Figure 2. KEGG and GO analyses of DEGs in renal cancer cells between 2D and 3D culture systems

(A) KEGG analysis (B) BP: Biological processes, (C) CC: Cellular components, (D) MF: Molecular functions. 

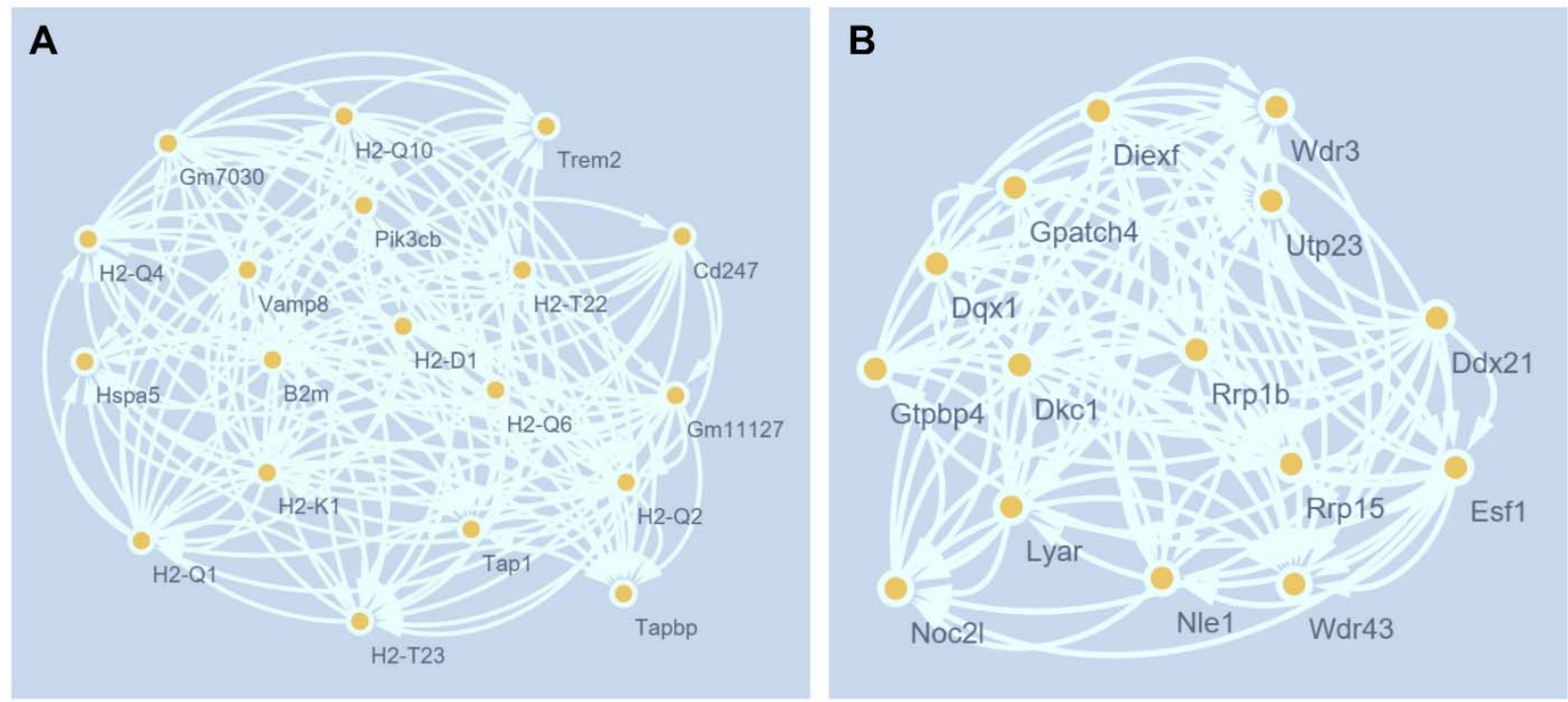

Figure 3. The PPI network analyses of DEGs in renal cancer cells between 2D and 3D culture systems

The cluster (A) and cluster (B) were constructed by MCODE. 
bioRxiv preprint doi: https://doi.org/10.1101/2022 0131.478529; this version posted February 2. 2022. The copyright holder for this preprint (which was not certified by peer review) is the author/funder, who has granted bioRxiv a license to display the preprint in perpetuity. It is made available under aCC-BY-NC-ND 4.0 International license.

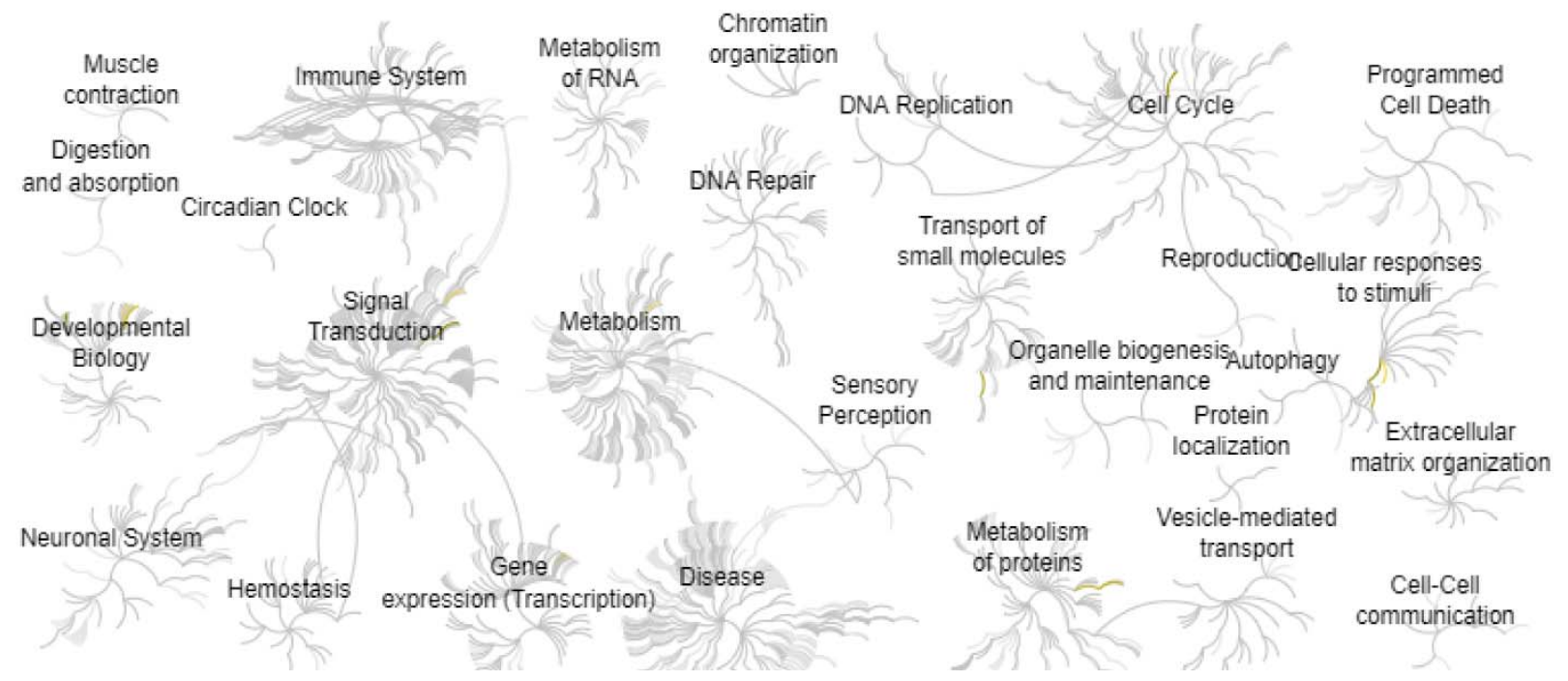

Figure 4. Reactome map representation of the significant biological processes in renal cancer cells between 2D and 3D culture systems 


\section{Table 1}

\begin{tabular}{llll}
\hline Entrez gene & Gene symbol & Fold-change & Regulation \\
\hline \multicolumn{2}{l}{ Top 10 down-regulated DEGs } & & \\
342527 & Smtnl2 & -4.098803795 & Down \\
545363 & Gm5833 & -3.899557414 & Down \\
2152 & F3 & -3.267920658 & Down \\
10841 & Ftcd & -3.251459755 & Down \\
9293 & Gpr52 & -3.219829955 & Down \\
10252 & Spry1 & -3.157431352 & Down \\
196410 & Mettl7b & -3.14920572 & Down \\
85477 & Scin & -3.128462553 & Down \\
100040843 & Cyp4a32 & -3.123319545 & Down \\
98736 & 1700034H15Rik & -2.87893792 & Down \\
Top 10 up-regulated DEGs & & \\
54209 & Trem2 & 6.286834421 & up \\
124599 & Cd300lb & 6.154935072 & up \\
79977 & Grhl2 & 5.388158156 & up \\
26115 & Tanc2 & 5.272378718 & up \\
5880 & Rac2 & 5.181825342 & up \\
12984 & Csf2rb2 & 4.94316349 & up \\
79745 & Clip4 & 4.923979988 & up \\
643418 & Lipn & 4.865791822 & up \\
4689 & Ncf4 & 4.85610423 & up \\
285489 & Dok7 & 4.788819374 & up \\
\hline
\end{tabular}




\section{Table 2. Top ten genes demonstrated by connectivity degree in the PPI network}

\begin{tabular}{lll}
\hline Gene symbol & Gene title & Degree \\
\hline MYC & $\begin{array}{l}\text { MYC proto-oncogene, bhlh transcription } \\
\text { factor }\end{array}$ & 97 \\
EGF & Epidermal growth factor & 83 \\
VEGFA & Vascular endothelial growth factor A & 78 \\
STAT3 & $\begin{array}{l}\text { Signal transducer and activator of } \\
\text { transcription 3 }\end{array}$ & 68 \\
NOTCH1 & Notch receptor 1 & 59 \\
CAT & Catalase & 54 \\
CCND1 & Cyclin D1 & 52 \\
HSPA8 & Heat shock protein family A (Hsp70) & 52 \\
& member 8 & 51 \\
DLG4 & Discs large MAGUK scaffold protein 4 & 51 \\
HSPA5 & Heat shock protein family A (Hsp70) & \\
& member 5 & \\
\hline
\end{tabular}




\section{References}

[1] Padala SA, Barsouk A, Thandra KC, Saginala K, Mohammed A, Vakiti A, Rawla P, Barsouk A:

Epidemiology of Renal Cell Carcinoma. World J Oncol 2020, 11:79-87.

[2] Hsieh JJ, Purdue MP, Signoretti S, Swanton C, Albiges L, Schmidinger M, Heng DY, Larkin J, Ficarra V:

Renal cell carcinoma. Nat Rev Dis Primers 2017, 3:17009.

[3] Cairns P: Renal cell carcinoma. Cancer Biomark 2010, 9:461-73.

[4] Chin AI, Lam JS, Figlin RA, Belldegrun AS: Surveillance strategies for renal cell carcinoma patients following nephrectomy. Rev Urol 2006, 8:1-7.

[5] Schenone M, Dancik V, Wagner BK, Clemons PA: Target identification and mechanism of action in chemical biology and drug discovery. Nat Chem Biol 2013, 9:232-40.

[6] Bayat Mokhtari R, Homayouni TS, Baluch N, Morgatskaya E, Kumar S, Das B, Yeger H: Combination therapy in combating cancer. Oncotarget 2017, 8:38022-43.

[7] Bidabadi SS, Jain SM: Cellular, Molecular, and Physiological Aspects of In Vitro Plant Regeneration.

Plants (Basel) 2020, 9.

[8] Fitzgerald AA, Li E, Weiner LM: 3D Culture Systems for Exploring Cancer Immunology. Cancers (Basel) 2020, 13.

[9] Yu G, Wang LG, Han Y, He QY: clusterProfiler: an R package for comparing biological themes among gene clusters. OMICS 2012, 16:284-7.

[10] Hanming G: nuotrophils arthritis. Research Square 2021.

[11] Jing L, Letian W, Hanming G: Identification of driver genes and biological signaling for alcoholic myopathy. Research Square 2021.

[12] Yuan G: Identification of biomarkers and pathways of mitochondria in sepsis patients. bioRxiv 2021:2021.03.29.437586.

[13] Jing W, Hanming G: Identification of biological processes and potential inhibitors for aging skin. Research Square 2021.

[14] Gu H, Wang W, Yuan G: Identification of biomarkers and candidate inhibitors for multiple myeloma. bioRxiv 2021:2021.02.25.432847.

[15] Gu H, Yuan G: Identification of potential biomarkers and inhibitors for SARS-CoV-2 infection. medRxiv 2020:2020.09.15.20195487.

[16] Edmondson R, Broglie JJ, Adcock AF, Yang L: Three-dimensional cell culture systems and their applications in drug discovery and cell-based biosensors. Assay Drug Dev Technol 2014, 12:207-18. [17] Solmonson A, DeBerardinis RJ: Lipoic acid metabolism and mitochondrial redox regulation. J Biol Chem 2018, 293:7522-30.

[18] Ward NP, DeNicola GM: Sulfur metabolism and its contribution to malignancy. Int Rev Cell Mol Biol 2019, 347:39-103.

[19] Brancaccio M, Russo M, Masullo M, Palumbo A, Russo GL, Castellano I: Sulfur-containing histidine compounds inhibit gamma-glutamyl transpeptidase activity in human cancer cells. J Biol Chem 2019, 294:14603-14.

[20] Diaz-Montero CM, Rini BI, Finke JH: The immunology of renal cell carcinoma. Nat Rev Nephrol 2020, 16:721-35.

[21] Muto A, Gridelli C: New immunotherapy in the treatment of advanced renal cancer. Expert Opin Emerg Drugs 2019, 24:233-7.

[22] Shroff EH, Eberlin LS, Dang VM, Gouw AM, Gabay M, Adam SJ, Bellovin DI, Tran PT, Philbrick WM, Garcia-Ocana A, Casey SC, Li Y, Dang CV, Zare RN, Felsher DW: MYC oncogene overexpression drives renal cell carcinoma in a mouse model through glutamine metabolism. Proc Natl Acad Sci U S A 2015, 112:6539-44. 
[23] Bouvard C, Lim SM, Ludka J, Yazdani N, Woods AK, Chatterjee AK, Schultz PG, Zhu S: Small molecule selectively suppresses MYC transcription in cancer cells. Proc Natl Acad Sci U S A 2017, 114:3497-502.

[24] Reppert SM, Weaver DR: Coordination of circadian timing in mammals. Nature 2002, 418:935-41.

[25] Yuan G, Hua B, Cai T, Xu L, Li E, Huang Y, Sun N, Yan Z, Lu C, Qian R: Clock mediates liver senescence by controlling ER stress. Aging 2017, 9:2647-65.

[26] Zhu Z, Hua B, Shang Z, Yuan G, Xu L, Li E, Li X, Sun N, Yan Z, Qian R, Lu C: Altered Clock and Lipid Metabolism-Related Genes in Atherosclerotic Mice Kept with Abnormal Lighting Condition. Biomed Res Int 2016, 2016:5438589.

[27] Xu L, Cheng Q, Hua B, Cai T, Lin J, Yuan G, Yan Z, Li X, Sun N, Lu C, Qian R: Circadian gene Clock regulates mitochondrial morphology and functions by posttranscriptional way. bioRxiv 2018:365452. [28] Yuan G, Xu L, Cai T, Hua B, Sun N, Yan Z, Lu C, Qian R: Clock mutant promotes osteoarthritis by inhibiting the acetylation of NFkappaB. Osteoarthritis Cartilage 2019, 27:922-31.

[29] Fan XF, Wang XR, Yuan GS, Wu DH, Hu LG, Xue F, Gong YS: [Effect of safflower injection on endoplasmic reticulum stress-induced apoptosts in rats with hypoxic pulmonary hypertension]. Zhongguo Ying Yong Sheng Li Xue Za Zhi 2012, 28:561-7.

[30] Zhu Z, Xu L, Cai T, Yuan G, Sun N, Lu C, Qian R: Clock represses preadipocytes adipogenesis via GILZ. J Cell Physiol 2018, 233:6028-40.

[31] Yuan G, Hua B, Yang Y, Xu L, Cai T, Sun N, Yan Z, Lu C, Qian R: The Circadian Gene Clock Regulates Bone Formation Via PDIA3. J Bone Miner Res 2017, 32:861-71.

[32] Mao SZ, Fan XF, Xue F, Chen R, Chen XY, Yuan GS, Hu LG, Liu SF, Gong YS: Intermedin modulates hypoxic pulmonary vascular remodeling by inhibiting pulmonary artery smooth muscle cell proliferation. Pulm Pharmacol Ther 2014, 27:1-9.

[33] Cai T, Hua B, Luo D, Xu L, Cheng Q, Yuan G, Yan Z, Sun N, Hua L, Lu C: The circadian protein CLOCK regulates cell metabolism via the mitochondrial carrier SLC25A10. Biochim Biophys Acta Mol Cell Res 2019, 1866:1310-21.

[34] Zhu Z, Hua B, Xu L, Yuan G, Li E, Li X, Sun N, Yan Z, Lu C, Qian R: CLOCK promotes 3T3-L1 cell proliferation via Wnt signaling. IUBMB Life 2016, 68:557-68.

[35] Burchett JB, Knudsen-Clark AM, Altman BJ: MYC Ran Up the Clock: The Complex Interplay between MYC and the Molecular Circadian Clock in Cancer. Int J Mol Sci 2021, 22.

[36] Favaro JP, George DJ: Targeted therapy in renal cell carcinoma. Expert Opin Investig Drugs 2005, 14:1251-8.

[37] Situ Y, Xu Q, Deng L, Zhu Y, Gao R, Lei L, Shao Z: System analysis of VEGFA in renal cell carcinoma: The expression, prognosis, gene regulation network and regulation targets. Int J Biol Markers 2021:17246008211063501.

[38] Mohassab AM, Hassan HA, Abdelhamid D, Abdel-Aziz M: STAT3 transcription factor as target for anti-cancer therapy. Pharmacol Rep 2020, 72:1101-24.

[39] Rosenbaum DM, Rasmussen SG, Kobilka BK: The structure and function of G-protein-coupled receptors. Nature 2009, 459:356-63.

[40] Yuan G, Yang S, Yang S: Macrophage RGS12 contributes to osteoarthritis pathogenesis through enhancing the ubiquitination. Genes \& Diseases 2021.

[41] Yuan G, Yang S, Yang S, Ng A, Oursler MJ: RGS12 is a critical proinflammatory factor in the pathogenesis of inflammatory arthritis via acting in Cox2-RGS12-NF kappa B pathway activation loop. J Bone Miner Res: WILEY 111 RIVER ST, HOBOKEN 07030-5774, NJ USA, 2019. pp. 147-.

[42] Xie K, Martemyanov KA: Control of striatal signaling by g protein regulators. Front Neuroanat 2011, 5:49.

[43] Fu C, Yuan G, Yang ST, Zhang D, Yang S: RGS12 Represses Oral Cancer via the Phosphorylation and SUMOylation of PTEN. J Dent Res 2020:22034520972095. 
[44] Yuan G, Yang S, Ng A, Fu C, Oursler MJ, Xing L, Yang S: RGS12 Is a Novel Critical NF-kappaB Activator in Inflammatory Arthritis. iScience 2020, 23:101172.

[45] Yuan G, Yang S, Gautam M, Luo W, Yang S: Macrophage regulator of G-protein signaling 12 contributes to inflammatory pain hypersensitivity. Ann Transl Med 2021, 9:448.

[46] Stewart A, Fisher RA: Introduction: G Protein-coupled Receptors and RGS Proteins. Prog Mol Biol Transl Sci 2015, 133:1-11.

[47] Yuan G, Yang S, Liu M, Yang S: RGS12 is required for the maintenance of mitochondrial function during skeletal development. Cell Discov 2020, 6:59.

[48] Yuan G, Fu C, Yang ST, Yuh DY, Hajishengallis G, Yang S: RGS12 Drives Macrophage Activation and Osteoclastogenesis in Periodontitis. J Dent Res 2021:220345211045303.

[49] Seki N, Sugano S, Suzuki Y, Nakagawara A, Ohira M, Muramatsu M, Saito T, Hori T: Isolation, tissue expression, and chromosomal assignment of human RGS5, a novel G-protein signaling regulator gene. J Hum Genet 1998, 43:202-5.

[50] Yuan G, Huang Y, Yang ST, Ng A, Yang S: RGS12 inhibits the progression and metastasis of multiple myeloma by driving $\mathrm{M} 1$ macrophage polarization and activation in the bone marrow microenvironment. Cancer Commun (Lond) 2022, 42:60-4.

[51] Pelletier S, Duhamel F, Coulombe P, Popoff MR, Meloche S: Rho family GTPases are required for activation of Jak/STAT signaling by $G$ protein-coupled receptors. Mol Cell Biol 2003, 23:1316-33.

[52] Liu S, Ma X, Ai Q, Huang Q, Shi T, Zhu M, Wang B, Zhang X: NOTCH1 functions as an oncogene by regulating the PTEN/PI3K/AKT pathway in clear cell renal cell carcinoma. Urol Oncol 2013, 31:938-48. [53] Pirincci N, Kaya TY, Kaba M, Ozan T, Gecit I, Ozveren H, Eren H, Ceylan K: Serum adenosine deaminase, catalase, and carbonic anhydrase activities in patients with renal cell carcinoma. Redox Rep 2017, 22:252-6.

[54] Li Z, Liu J, Zhang X, Fang L, Zhang C, Zhang Z, Yan L, Tang Y, Fan Y: Prognostic Significance of Cyclin D1 Expression in Renal Cell Carcinoma: a Systematic Review and Meta-analysis. Pathol Oncol Res 2020, 26:1401-9.

[55] Li J, Ge Z: High HSPA8 expression predicts adverse outcomes of acute myeloid leukemia. BMC Cancer 2021, 21:475.

[56] Ye Y, Li SL, Wang SY: Construction and analysis of mRNA, miRNA, IncRNA, and TF regulatory networks reveal the key genes associated with prostate cancer. PLoS ONE 2018, 13:e0198055.

[57] Song S, Long M, Yu G, Cheng Y, Yang Q, Liu J, Wang Y, Sheng J, Wang L, Wang Z, Xu B: Urinary exosome miR-30c-5p as a biomarker of clear cell renal cell carcinoma that inhibits progression by targeting HSPA5. J Cell Mol Med 2019, 23:6755-65. 